ISSN 2693-2490

\title{
A Case of Recurrent Acute Abdomen in a Young Lady Masquerading as Somatoform Disorder
}

\author{
Journal of Psychology and Neuroscience
}

Case Report

\author{
Richmond Ronald Gomes \\ Associate Professor of Medicine, Ad-din Women's Medical College \\ Hospital, Dhaka, Bangladesh
}

\author{
*Correspondence author \\ Richmond Ronald Gomes \\ Associate Professor of Medicine \\ Ad-din Women's Medical College Hospital, Dhaka \\ Bangladesh \\ Orchid ID : 000000225117972
}

Submitted : 19 Jun 2021 ; Published : 5 Jul 2021

\begin{abstract}
Acute intermittent porphyria (AIP) is a rare autosomal dominant hereditary metabolic disorder having protean manifestations. It usually presents with short duration of gastrointestinal symptoms followed by rapidly progressivefulminant neurological syndrome. It is a neurological emergency and mimics many other psychiatric and medical disorders and can be fatal if it remains undiagnosed and untreated. Further, specifictreatment in the form of Heme arginate is not universally available and very costly, so high clinical suspicion and early diagnosis and management of acute attack and prevention of further attacks are very important. Here, we report a 23 years old married female nurse presenting with recurrent acute abdomen requiring frequent hospital admissions along with convulsion during her last attack. The presence of porphyrins in urine confirms the diagnosis of AIP.
\end{abstract}

Keywords : Aute Abdomen, Convulsion, Porphyrin

\section{Introduction}

Acute intermittent porphyria (AIP) is an autosomal dominant disorder, resulting from partial deficiency of porphobilinogen deaminase (PBGD) enzyme in the haem biosynthetic pathway [1]. The presentation of AIP as an acute abdomen is well known, but a short durationof gastrointestinal symptoms followed by a rapidly progressive course of neuropsychiatric manifestationsincluding peripheral neuropathy, respiratory paralysis, seizures and loss of consciousness during the first attack may also occur. The relationship of seizures with porphyria is complex and the most common description is the presence of acute symptomatic generalized seizure occurring in the context of AIP in relapse [2].Convulsive seizure may be the presenting symptom of an acute relapse [3]. The knowledge of convulsionin AIP is very essential because the use of enzymeinducing antiepileptic drugs can cause worsening of the convulsion leading to death. Thus, a strong clinical suspicion, early diagnosis and adequate management of convulsion and prevention of further attacks are ofparamount importance in reducing the morbidity and mortality. We present a report of a 23 year old female nurse who presented with recurrent acute abdomen with convulsion during her last attack.

\section{Case Report}

Mrs. X, a 23 years old married, muslim female nurse presented to me with the complaints of diffuse abdominal pain for 5 days, vomiting for several episodes for 3 days and constipation for the same duration. Abdominal pain was severe, excruciating, diffuse, sudden onset but gradually increasing, constant, nonradiating in nature. The pain was neither related with taking meals or with empty stomach nor relieved by taking any posture or taking any antispasmodics, proton pump inhibitors or antacid. Vomiting was projectile and not profuse, contained bile stained food material. There was nausea along with vomiting. There was also absolute constipation for the last 3 days with no passage of flatus. There was no history of fever, weight loss, altered bowel habit,passage of fatty, bloody or mucoid stool, hematemesis or melana, abdominal distension, joint pain, rash, cough. She also denied any sexual promiscuity or contact with any patient with active tuberculosis.On query, she had H/O recurrent attacks of same type of abdominal pain for last one year, for which she admitted repeatedly in local hospitals where she was treated with NPO and intravenous fluids and analgesics with symptomatic improvement. She also had history of taking intravenous opiates at home by herself. There was no history of consanguity of marriage or any other chronic illness in her family. Menstrual history was normal with the patient was in the luteal phase during presentation. She was on OCP since last 2 years. On examination, she was conscious, oriented but sick looking and emaciated.Pulse: $78 / \mathrm{min}$, regular, good in volume and normal in character, bilaterally synchronous, all peripheral pulses were palpable. R-R- 16 breaths/min, abdomino-thoracic, BP- 110/70 mm of $\mathrm{Hg}$, no postural drop.Pallor- present,Hair, skin- normal with no rash, no icterus, clubbing or other nail changes, no lymphadenopathy,no joint swelling, and spine examination was normal. Abdominal examination revealed non distended, 
diffusely tender abdomen with very sluggish bowel sound. There were no organomegaly or any evidence of ascites. Other systematic examination revealed no abnormalities. On initial investigation, $\mathrm{CBC}$ revealed mild microcytic hypochromic anemia with $\mathrm{Hb} \%-8.8 \mathrm{gm} \%$ (normal 12-16 mg\%), MCV-72.4Fl (normal 76-96 fL), MCH-23.6pg(normal 28-36 pg), and Total WBC count including differentials and platelet counts were within normal limit. ESR was $38 \mathrm{~mm}$ in 1sthr. Liver function tests, s. creatinine, Urine R/E, beta- hCG, s.lipase, USG of whole abdomen and endoscopy of UGIT and CT abdomen revealed no definite abnormalities. X-ray abdomen revealed multiple distended bowel lops with no definite air fluid level. Her s. electrolyte showed hyponatremia withsodium 122 $\mathrm{mmol} / \mathrm{L}$. Thyroid function tests and basal cortisol was normal. Patient was started managing conservatively with nothing per oral, intravenous fluids, intravenous opiates and proton pump inhibitors with minimal relief of her symptoms. On the 3rd day of admission she developed one episode of witnessed generalized tonic-clonic seizure, she also complained of severe back and proximal muscle pain. Repeat examination revealed, patient was not so well oriented with some features of psychosis (self-spitting, lip smacking), tachycardia with pulse $102 / \mathrm{min}$, regular, raised $\mathrm{BP}$ of $160 / 95 \mathrm{~mm}$ of $\mathrm{Hg}$, abdomen was non tender with sluggish bowel sounds and no ascites or organomegaly or lump. There was proximal pelvic girdle weakness. Repeat s. electrolyte showed persisting hyponatremia with sodium $127 \mathrm{mmol} / \mathrm{L}$. The clinical scenario and presence of dark urine raised the suspicion of acute intermittent porphyria(AIP), further investigation revealed urinary sodium $48 \mathrm{mmol} /$ day, S. osmolality $266 \mathrm{mosm} / \mathrm{kg}$ (proving the SIADH dure to AIP). NCS of limbs could not be done due to financial constraints. 24 hours porphobilinogen was sent which revealed 41.8 $\mathrm{mg} /$ day (normal $<3.4 \mathrm{mg} /$ day). She was started treatment with fluid restriction, high carbohydrate intravenous fluids, Prochlorperazine as anti-emetic, intravenous opiatwes as analgesic, gabapentin as anti-epileptic and beta blocker for autonomic neuropathy (tachycardia and hypertension). With treatment her condition improved. After 2 weeks on outpatient door follow up, she was conscious, oriented having no further episode of seizure and improved abdominal and back pain and proximal muscle weakness.Bowel movement was regular with no vomiting.Repeated S. Electrolyte revealed Na-136, K-4.2, Cl-92, HCO3-26.Vitals were stable with pulse $78 / \mathrm{min}$, regular, $\mathrm{BP}$ was $110 / 70 \mathrm{~mm}$ of $\mathrm{Hg}$. She was properly advised regarding avoidance of precipitating factors including drugs.

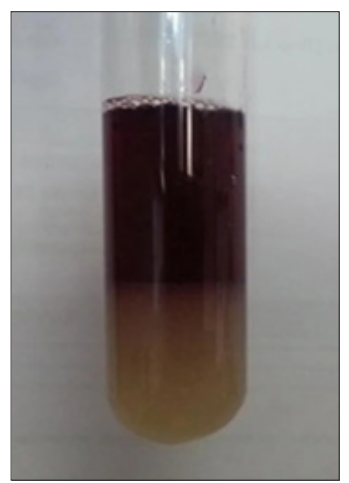

Figure 1: Dark color urine of the patient

\section{Discussion}

The porphyrias are a group of rare metabolic disorders due to reduced metabolic activity of any of the enzymes in heme bio synthetic pathway. The disorder may be either acquired or inherited due to defective gene encoding the enzyme. The deficiency of any of the enzymes causes diverse clinical symptoms such as neurovisceral, cutaneous or mixed [3-5]. Porphyrins are intermediate product in the heme biosynthetic pathway. Heme is an essential component for both cellular hemoproteins produced mainly in the bone marrow which makes hemoglobin; in the liver the metablozing enzymes cytochromes P450s are formed. The first step is the formation of $\partial$ - aminolevulinic acid (ALA) from glycine and succinyl coenzyme A. The other steps are:

1. synthesis of substituted pyrol compound porphobilinogen

2. condensation of 4 porphobilinogen molecule to yield porphyrinogen

3. modification of side chain and ring and

4. introduction of iron to form heme. If no heme is present to inhibit the pathway, production of heme continues unopposed. Only protoporphyrin is used for heme synthesis. The other porphyrins have no physiologic functions and must be excreted; proto and coproporphyrins in feces; uro and coproporphyrins in urine and plasma $[6,7]$.

Acute intermittent porphyria (AIP), a rare autosomal dominant disorder is the most common type of porphyria that results from an approximately $50 \%$ deficiency of enzyme porphobilinigen (PBG) deaminase. The epidemiology of AIP is complicated because of its rarity and delay in diagnosis. The prevalence of AIP varies with a higher incidence in England, Ireland and Scandinivia, the prevalence of AIP in general adult population ranges between $1 \& 8$ per lakh [8].

The clinical feature of AIP may manifest at any age from puberty onwards but most commonly occurs in the third decade of life. Abdominal pain, peripheral neuropathy and changes in the mental status are the classical triad of an acute attack [9]. The clinical manifestations include neuropsychiatric symptoms and clinical signs (hysteria, anxiety, depression, phobia, agitation, psychosis, seizure, neuropathy), autonomic instability (hypertension, tachycardia, abdominal pain, nausea, vomiting, constipation), dehydration and electrolyte imbalance (hyponatremia, hypokalemia, hypocalcemia) [4]. The peripheral neuropathy tends to be progressive and involves motor and sensory nerves. Muscular weakness may proceed to quadriparesis, respiratory paralysis and arrest which may resemble Guillain -Barre syndrome [10]. The diagnosis of AIP depends on clinical history and increased amount of porphyrins or porphyrin precursors in the urine, feces and blood. The presence of reduced erythrocyte PBG deaminase activity (PBGD) helps to confirm the diagnosis. The Watson-Swartz is the is the most widely used screening test and is approximately $95 \%$ sensitive and specific for PBGD activity but test cannot differentiate AIP from other porphyrin disorders. Molecular analysis is the gold standard [11,12]. In the absence of sophisticated facilities, Wood's lamp could be 
an alternative diagnostic tool to detect the excess of porphyrins in teeth, urine, stool samples, red blood cells, and in blister fluid in different form of porphyrias. Addition of dilute hydrochloric acid to the sample being examined intensifies the fluorescence by converting porphyrinogens to porphyrins. Porphyrins appear intensely red when exposed to long wave ultraviolet light (UV-A). This makes them visible by Wood's lamp and enables them to measure accurately with a spectroflurometer [13].

Treatment strategies for AIP are focused on supportive and preventive measures. The precipitation of acute attack of AIP can result from exogenous factors that increases the synthesis of microsomal cytochrome P450 in the liver such as sulphonamides, barbiturates, sex hormones, chloroquine, griseofulvin and many other drugs, acute infections, luteal phase of menstrual cycle, fasting states and overindulgence of alcohol [14].

Seizures are corrected by treatment of hyponatremia. Many anticonvulsant drugs exacerbate acute porphyria. Clonazepum is less harmful than phenytoin, barbiturate or valproic acid. Bromide, gabapentin, vigabatrin are safe [15]. Cimetidine is a cost effective alternative to hemin to treat acute attacks, using $800 \mathrm{mg} /$ day until ALA level are reduced to normal levels. Patients are advised to follow a well-balanced diet with $60 \%$ to $70 \%$ energy from carbohydrate.

\section{Conclusion}

Diagnosis of AIP should be based on high degree of clinical suspicion. The constellation of diverse symptoms involving multiple systems makes the diagnosis difficult. AIP is a life threatening disease, so correct diagnosis, proper management stratigies regarding abortive and preventive therapies, treatment of acute crisis and to focus on preventing chronic complications are crucial to save the life of the patient. The patient and his/her relatives should be referred to genetic specialists for family screening and counselling.

\section{References}

1. Anderson K, Sassa S, Bishop D, Desnick R (2001) Disorder of hemebiosyn-thesis: $\mathrm{X}$ linked sideroblastic anemia and the porphyries. In: Scriver C, Beauder A, Sly W, Valley D, Childs B, Kinzler K, et al, eds. Metabolic and Molecular Bases of Inherited Disease. McGraw Hill: New York; 2001. p. 2991-3062.

2. Winkler AS, Peters TJ, Elwes RD (2005) Neuropsychiatric porphyria in patients with refractory epilepsy: Report of three cases. J Neurol Neurosurg Psychiatry 2005;76: 380 383.

3. Thadani H, Deacon A, Peters T (2000) Diagnosis and management of porphyria. BMJ 320(7250): 1647-1651.

4. Elder GH, Haft RJ, Meissner PN (1997) The acute porphyrias, The Lancet 349: 1613-1617.

5. Gonzalez Arriaza HL, BostwickJM (2003) Acute porphyrias: A case report and review. Am J Psychiatry 160(3): 450-458.

6. Abel G, Palmer Toy G (2002): Heme synthesis and catabolism, In: McClatchey KD (Eds), Clinical Laboratory Medicne (2 $\left.2^{\text {nd }} \mathrm{edn}\right)$, Lippincott Williams \& Wilkins USA pp 407-417.

7. Kappas A, Sassas S, Galbraith RA, Nordmann Y(1997), The porphyrias In: Scriver CR, Beaudet AL, Sly WS, Walle D,(Eds), the metabolic and molecular basis of inherited disease ( $7^{\text {the }}$ dn $)$, Mc Graw-Hill, USA, pp. 21032159.

8. Ackner B, Cooper JE, Gray CH, Kelly M (1962) Acute porphyria: a neuropsychiatric and biochemical study. Journal of psychomatic research 6(1): 521-523.

9. Regan L, Gonsalves L, TesarG (1999) Acute intermittent porphyria, psychosomatics 40(6): 521-523.

10. Tefferi A, Colgan JP, Solberg LA (1994) Acute intermittent porphyria: diagnosis and management, Mayo ClinProc 69(10): 991-995.

11. Elder GH, Smith SG, Smyth SJ (1990). Laboratory investigations of porphyrias. Ann ClinBiochem 27: 395412

12. Palmer KM (2006): Abdominal pain due to acute intermittent porphyria: When is the sound of hoof beats not horses, but zebras?A case report. DimensCrit Care Nurs 25(3): 103-109.

13. HalprinKM (1967): Diagnosis with Wood's light: The porphyrias, JAMA 200(6):460.

14. 2017: American Porphyria Foundation

15. Ahmed M, Ahmed MS, Patwari MI, Miah MT, Hasan MK et al(2015) Mymensing Med J 24(2): 420-423.

Copyright: (C2021 Richmond Ronald Gomes. This is an open-access article distributed under the terms of the Creative Commons Attribution License, which permits unrestricted use, distribution, and reproduction in anymedium, provided the original author and source are credited. 